\title{
Experimental study on the absorption characteristics of resonance-type brick/block walls
}

\author{
Hikari Mukai, ${ }^{*}$ Shinichi Sakamoto, ${ }^{* *}$ and Hideki Tachibana** \\ *Ono Sokki Co., Ltd., \\ 1-16-1, Hakusan, Midori-ku, Yokohama, 226-8507, Japan \\ **Institute of Industrial Science, University of Tokyo, \\ 4-6-1, Komaba, Meguro-ku, Tokyo, 153-0041 Japan \\ (Received 4 January 1999)
}

\begin{abstract}
Brick/block absorbing walls with openings backed with porous materials are often used for sound absorptive treatments in buildings. This type of brick/block walls have a frequencyselective sound absorption at low frequencies, which is usually explained as the Helmholtz resonance. In addition, they often have peaks of sound absorption at frequencies much different from the Helmholtz resonance frequency. In this paper, the sound absorption mechanism of this type of walls was investigated by experiments. As a result, it has been confirmed that the sound absorption is caused by the effect of open-pipe resonance which happens in the openings. In the case of brick/block sound absorptive constructions made of materials with a thickness of about $10 \mathrm{~cm}$, sound absorption caused by the open-pipe resonance is considerably significant at high frequencies. Therefore, when this type of sound absorption construction is used for room acoustic treatment, sound absorption at high frequencies must be carefully considered in acoustical design.
\end{abstract}

Keywords : Sound absorption, Brick/block wall, Open-pipe resonance, Scale model experiment, Kundt's method

PACS number: 43.20. Ks, 43.55. Dt ; 43.55. Ev

\section{INTRODUCTION}

Walls made of bricks or blocks with openings, backed with porous materials, are often used for sound absorptive treatments in buildings. This type of brick/block wall is usually viewed as a kind of resonance-type sound absorptive construction; the frequency at which sound absorption peaks can be calculated by the equation for the Helmholtz resonance. However, in the measurement results of sound absorption coefficient of this type of construction, peaks of sound absorption are often seen at frequencies much different from the Helmholtz resonance frequency. This phenomenon has never been explained, and it is scarcely considered in actual acoustical design. In order to investigate the sound absorption mechanism of this type of brick/block walls, experimental studies were performed.

\section{EXAMPLES OF SOUND ABSORP- TION CHARACTERISTICS OF BRICK/ BLOCK WALLS WITH OPENINGS}

Figures $1^{1)}$ and 2 show two examples of the sound absorption characteristics of brick/block walls with openings measured by the reverberation room method. The Helmholtz resonance frequency $f_{0}$ calculated from Eq. (1) is $198 \mathrm{~Hz}$ for the former case and $107 \mathrm{~Hz}$ for the latter case.

$$
f_{0}=\frac{c}{2 \pi} \sqrt{\frac{S}{l_{\mathrm{e}} \cdot V}}
$$

where, $c$ is the sound velocity, $S$ is the sectional area of the neck of the resonator, $l_{\mathrm{e}}$ is the effective length of the neck $\left(l_{\mathrm{e}}=l+0.8 d\right.$, where $d$ is a diameter of 


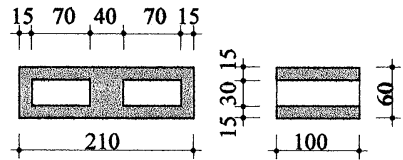

(a) Geometry of single brick

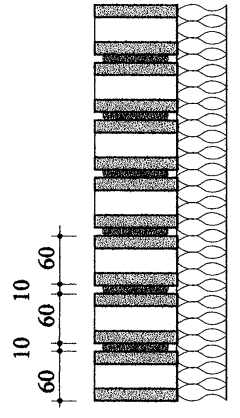

$+100 \nmid 55 \nmid 95+$

(b) Section of piled bricks

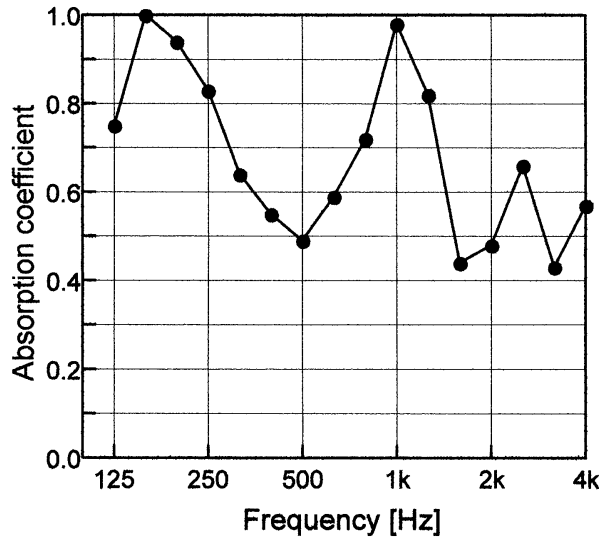

(c) Absorption characteristics (measured by Taisei Corp.)

Fig. 1 Absorptive wall of porous bricks.

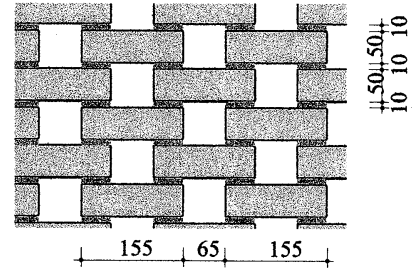

(a) Plan

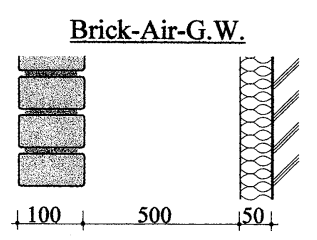

(b) Section

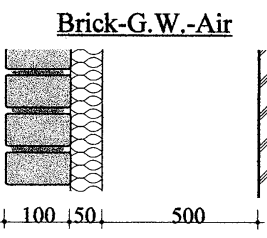

Fig. 2 Absorptive wall of piled bricks. the section), and $V$ is the volume of the cavity of the resonator.

In Fig. 1 and 2, it is clearly seen that the sound absorption coefficient peaks at around these resonance frequencies in each case. This fact indicates that the sound absorption in low frequency range is caused by the Helmholtz resonance.

In addition to this kind of sound absorption, however, other sharp peaks are seen at much higher frequencies in both cases; at $1 \mathrm{kHz}$ for the former and $1.25 \mathrm{kHz}$ for the latter. In order to investigate the mechanism of this kind of sound absorption in high frequencies, the following two experiments were performed.

\section{SCALE MODEL EXPERIMENT}

As the first experimental study, $1 / 10$ scale model experiments were performed. Table 1 shows the 
Table 1 Variation of the model specimens.

\begin{tabular}{|c|c|c|c|c|c|c|}
\hline & \multirow[b]{5}{*}{$t$} & \multirow[b]{5}{*}{$L$} & \multirow[b]{5}{*}{ Opening type } & \multicolumn{3}{|c|}{ Conditions of the backing space } \\
\hline & & & & $\frac{\text { Perforated panel }}{(\text { thickness }} 1$ ) & Perforated panel $(t)$ & Perforated panel $(t)$ \\
\hline & & & & Felt cloth (thickness:F) & Air space $(\mathrm{L})$ & Air spac $(\mathrm{L})$ \\
\hline & & & & Air space(thickness:L) & & \\
\hline & & & & $\mathbb{R} \mathbb{R} \mathbb{R}$ & $\pi \| \pi$ & $\mathbb{R} \mathbb{R} \mathbb{R}$ \\
\hline \multirow{2}{*}{$\mathbf{A}$} & \multirow{2}{*}{10} & \multirow{2}{*}{60} & Square & (1) $t 10-F 1-L 60$ & (2) $t 10-L 60-F 1$ & (3) $t 10-L 60$ \\
\hline & & & Circle & (4) $t 10-F 1-L 60$ & (5) $t 10-L 60-F 1$ & (6) $t 10-L 60$ \\
\hline B & 10 & 10 & Square & (7) $t 10-F 1-L 60$ & (8) $t 10-L 60-F 1$ & (9) $t 10-L 60$ \\
\hline $\mathbf{C}$ & 20 & 60 & Circle & (10) $t 20-F 1-L 60$ & (11) $t 20-L 60-F 1$ & (12) $t 20-L 60$ \\
\hline
\end{tabular}

$t:$ thickness of perforated panel, $F$ : thickness of porous material (felt cloth), unit $[\mathrm{mm}]$

$L$ : depthe of backing space.

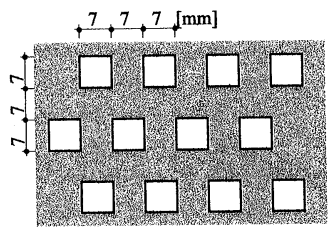

(a) Square opening

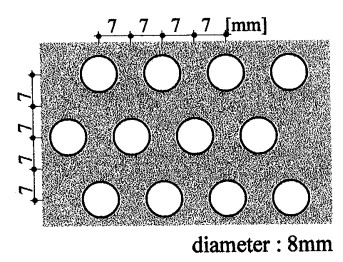

(b) Circular opening
Fig. 3 Plan of the model specimens.

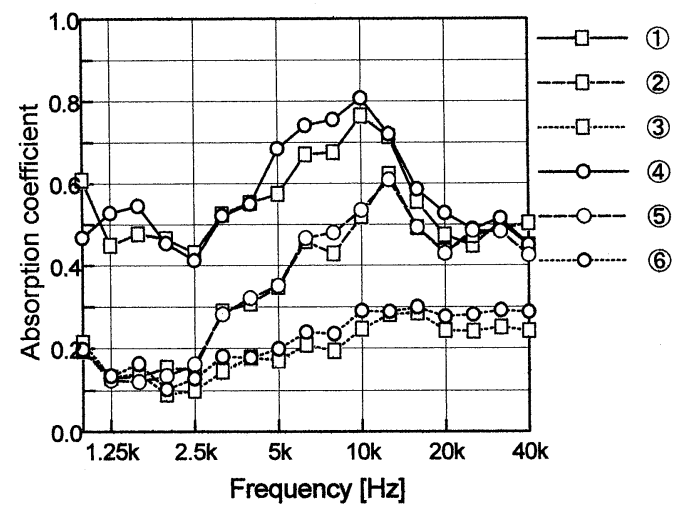

Fig. 4 Measurement result of condition A. Board : $10 \mathrm{~mm}$ thick, backing space : $60 \mathrm{~mm}$.

model specimens used for the experiments which are made of acrylic resin boards of 10 or $20 \mathrm{~mm}$ thickness with square or circular openings as shown in Fig. 3. The total number of specimens was 12 as shown in Table 1 , by varying the condition in the backing space: with or without porous material (1

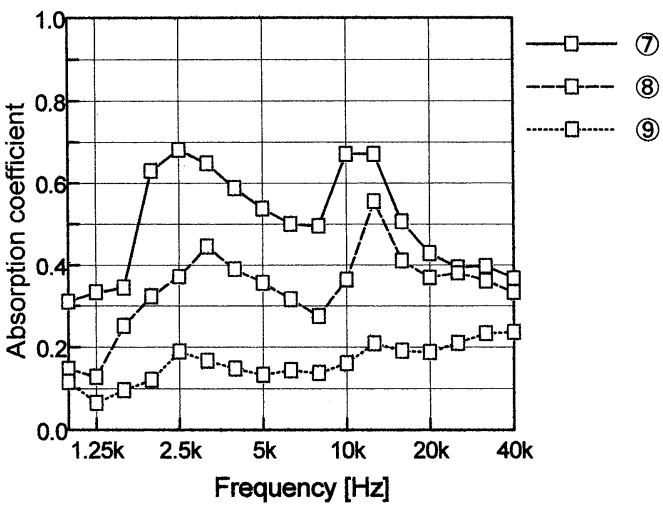

Fig. 5 Measurement result of condition B. Board : $10 \mathrm{~mm}$ thick, backing space : $10 \mathrm{~mm}$.

$\mathrm{mm}$ thick felt cloth) and by varying its position in the air space.

The sound absorption coefficient measurements for these specimens were performed using a scale model reverberation room of $0.2 \mathrm{~m}^{3}$ air volume by the noise-interrupted method. In order to stabilize the acoustical condition of medium, the air in the model reverberation room was substituted by $\mathrm{N}_{2}$ gas. ${ }^{2)}$

The representative measurement results are shown in Fig. 4 to Fig. 6 . From these data, the following results can be seen.

(1) In the case of condition A (board : $10 \mathrm{~mm}$ thick, backing air space : $60 \mathrm{~mm}$, see Table 1 and Fig. 4), a sharp peak is seen in sound absorption coefficient at $10-12.5 \mathrm{kHz}(1-1.25 \mathrm{kHz}$ in real frequency). This is very similar to the result 


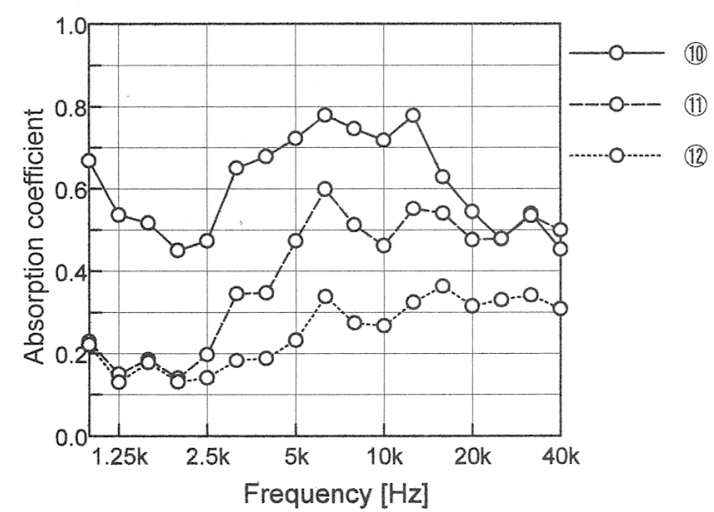

Fig. 6 Measurement result of condition C. Board : $20 \mathrm{~mm}$ thick, backing space : $60 \mathrm{~mm}$.

shown in Fig. 2. In this case, the results for the circular and square openings are almost the same.

(2) In the case of condition B (board: $10 \mathrm{~mm}$ thick, backing air space: $10 \mathrm{~mm}$, see Table 1 and Fig. 5), peaks of sound absorption coefficient are seen not only at the Helmholtz resonance frequency $(2.1 \mathrm{kHz})$ but also at $12.5 \mathrm{kHz}$.

(3) In the case of condition C (board : 20 mm thick, backing air space: $60 \mathrm{~mm}$, see Table 1 and Fig. $6)$, the peak of the sound absorption coefficient moved to $630 \mathrm{~Hz}$ and other peaks are seen at $1.25-1.6 \mathrm{kHz}$ and $3.15 \mathrm{kHz}$. (In this case, the Helmholtz resonance frequency is $680 \mathrm{~Hz}$ and it is outside of the measurement frequency range.)

\section{CONSIDERATIONS OF SOUND ABSORPTION MECHANISMS}

By examining the data on the sound absorption coefficient of the real brick/block walls and scale model perforated panel walls presented above, it can be seen that the sharp sound absorption at frequencies much higher than $f_{0}$ calculated by Eq. (1) is caused by a sound absorption mechanism other than the Helmholtz resonance. To explain this additional absorption, it is natural to ascribe it to the open-pipe resonance at the opening (neck) of the brick/block or the perforated panel of the scale model specimens. In the case where the depth of the opening is $100 \mathrm{~mm}$ (10 $\mathrm{mm}$ in $1 / 10$ scale model), the first open-pipe resonance frequency $(n=1)$ is $1.36 \mathrm{kHz}(13.6 \mathrm{kHz}$ in $1 / 10$ scale model) according to the following equation.

$$
f_{n}=\frac{n \cdot c}{2 l_{e}}
$$

At these frequencies, the peaks of sound absorption are seen both in the real wall (Fig. 2) and the scale model wall (Fig. 4 and Fig. 5).

As shown in Fig. 6, when the thickness of the model perforated panel changed to $20 \mathrm{~mm}$, the frequency of peak absorption became one-half of the value of the frequency for a $10 \mathrm{~mm}$ thickness. Other peaks of sound absorption are seen at frequencies of twice and four times the first resonance frequency. These facts support the validity of the explanation mentioned above. That is, two kinds of resonance phenomena (Helmholtz resonance and open-pipe resonance) can arise with this kind of sound absorption constructions.

\section{VISUALIZATION EXPERIMENT BY THE KUNDT'S METHOD}

In order to examine the sound absorbing mechanism mentioned above, a visualization experiment was performed by applying the Kundt's dust-tube method. ${ }^{3-5)} \quad$ Figure 7 shows the apparatus made for the experiment. This box is made of polyvinyl chloride board; the upper surface is made of transparent acrylic resin board. In the box, two Helmholtz resonators were installed as shown in Fig. 7. In this experiment, the smaller resonator having the dimensions shown in Fig. 8 and a Helmholtz resonance frequency of $240 \mathrm{~Hz}$ was used. To visualize the movement of the air excited acoustically, cork dust was uniformly scattered on the floor. As the sound source, a driver unit of a horn speaker was mounted on the side of the box and a pure tone was radiated.

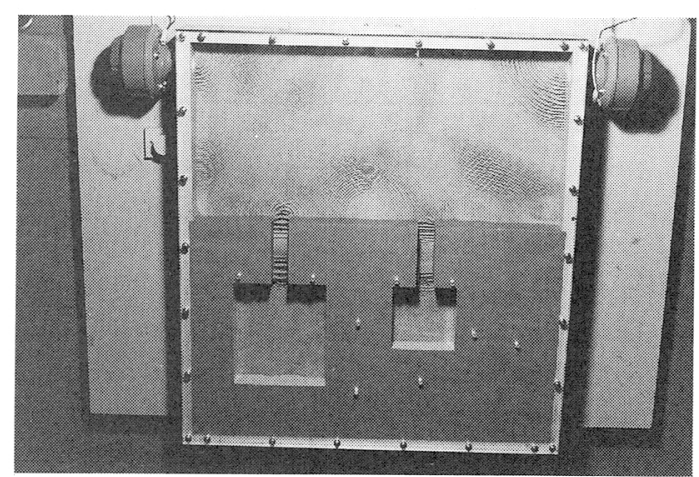

Fig. 7 Apparatus for the visualization of Helmholtz resonator. 


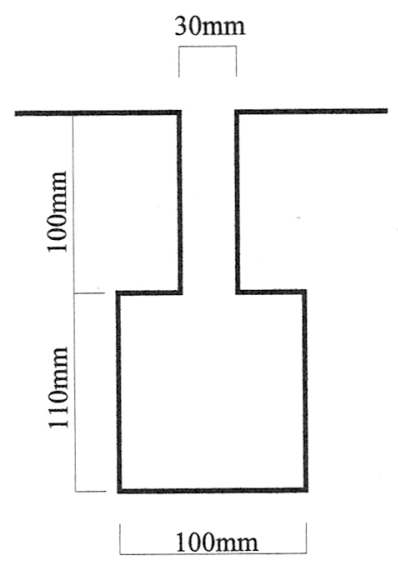

(Thickness: 50mm)

Fig. 8 Dimensions of the apparatus.

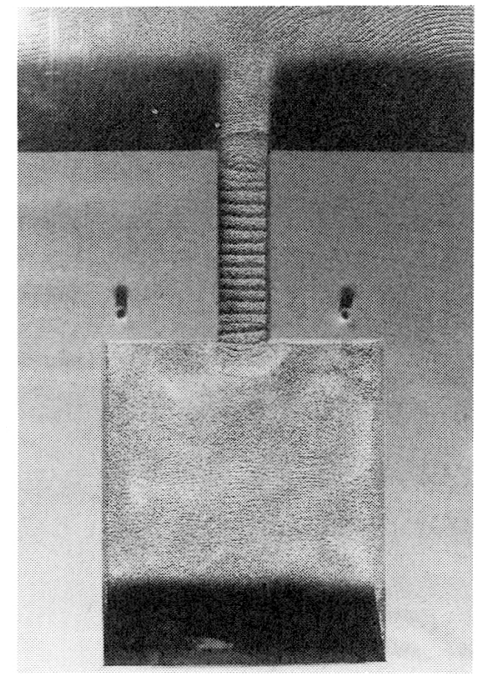

Fig. 9 Helmholtz resonance of the resonator.

In the experiment, the movement of the cork dust was observed by changing the exciting frequency. As a result, the cork dust was violently excited at a frequency of $210 \mathrm{~Hz}$ which is close to the calculated Helmholtz resonance frequency and uniform striped patterns were observed inside the neck as shown in Fig. 9.

Further, by increasing the source frequency to $1,250 \mathrm{~Hz}$, it was clearly observed that the cork dust was intensively excited again. In this case, the striped patterns were concentrated in the vicinity of the both ends of the neck as shown in Fig. 10. The

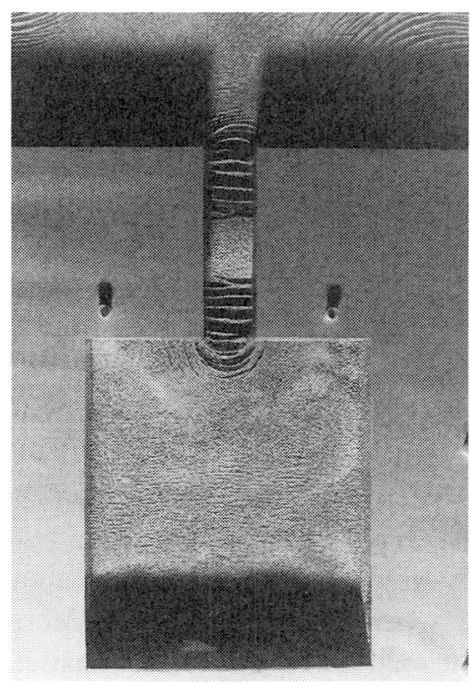

Fig. 10 Open-pipe resonance of the resonator.

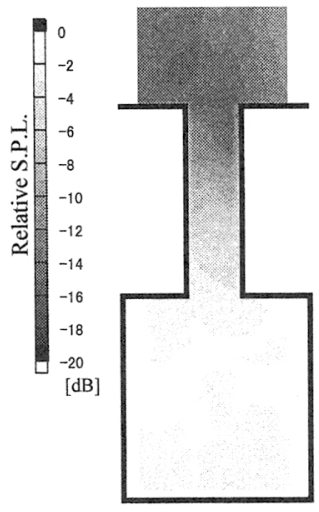

(a) $250 \mathrm{~Hz}$

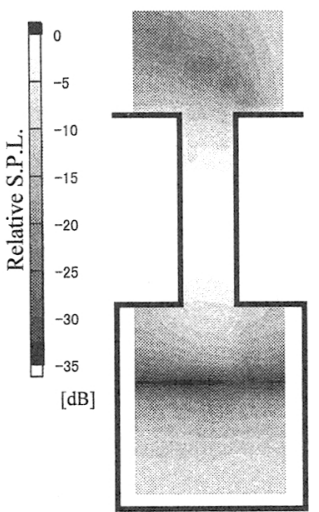

(b) $1250 \mathrm{~Hz}$
Fig. 11 Measurement results of sound pressure distribution around the resonator.

frequency is very close to $1,240 \mathrm{~Hz}$ which is calculated as the first $(n=1)$ resonance frequency of the open-pipe with a length of $10 \mathrm{~cm}$ by Eq. (2).

Next, the sound pressure inside the neck of the resonator when it was excited by a pink noise was measured by inserting a small pre-polarized condenser microphone. The output signal of the microphone was analyzed by the FFT method (frequency resolution: $2.5 \mathrm{~Hz}$ ). Figure 11 shows the measurement results of sound pressure distribution for $250 \mathrm{~Hz}$ and $1,250 \mathrm{~Hz}$. In these results, it can be seen that the sound pressure is gradually decreased 
from the cavity to the mouth of the neck in the case of $250 \mathrm{~Hz}$ (the Helmholtz resonance frequency), whereas the sound pressure is maximum at the center of the neck and minimum at its both ends in the case of $1,250 \mathrm{~Hz}$ (the first resonance frequency of the open-pipe).

\section{CONCLUSIONS}

Through the experimental studies mentioned above, it has been confirmed that in the case of brick/block sound absorptive constructions made of materials with a thickness of about $10 \mathrm{~cm}$, the openpipe resonance happens in addition to the Helmholtz resonance and its effect is considerably significant at high frequencies of about $1 \mathrm{kHz}$. Therefore, when this type of sound absorption construction is used for room acoustic treatment, sound absorption at frequencies other than the Helmholtz resonance frequency must be carefully considered in acoustical design. The same phenomenon might happen for general perforated panel constructions, but the open-pipe resonance is at much higher frequencies and therefore the effect can be neglected.
In this paper, the experimental studies performed for the investigation of the sound absorption mechanism of brick/block walls have been presented. Regarding this problem, the authors are now making a numerical investigation and the result will be presented in another paper.

\section{REFERENCES}

1) H. Tachibana, "Brick and block for sound absorption," Archit. Acoust. Noise Control 13(4), 34-37 (1984).

2) H. Tachibana, K. Ishii, and O. Hirano, "Acoustic model experiment by $\mathrm{N}_{2}$ substitution method," J. Acoust. Soc. Jpn. (J) 26, 163-169 (1971) (in Japanese).

3) K. Sato and M. Koyasu, "The effect of room shape on the sound field in room," J. Acoust. Soc. Jpn. (J) 13, 231-241 (1957) (in Japanese).

4) K. Sato, M. Koyasu, S. Nakamura, K. Kubo, and Y. Miyahara, "The illustration of sound field distribution in a model room by means of dust figure," J. Acoust. Soc. Jpn. (J), 16, 34-41, (1960).

5) H. Tachibana, S. Sakamoto, and H. Mukai, "Visualization of acoustic resonance phenomena by the Kundt's method," Proc. ASVA97, 571-574 (1997). 